\title{
Study of postoperative chest infections with particular emphasis on those caused by Haemophilus influenzae
}

\author{
GM TEBBUTT \\ From the Public Health Laboratory, South Cleveland Hospital, Middlesbrough, Cleveland
}

SUMMARY Fifteen per cent of patients admitted to a male general surgical ward were found to be carrying Haemophilus influenzae. Except for patients with chronic bronchitis, who developed an infection with the same micro-organism, carriage did not predispose patients to postoperative chest infection. Age, heavy smoking, and abdominal surgery increased the likelihood of respiratory infection after operation. $H$ influenzae accounted for $58 \%$ of bacterial pathogens isolated from sputum, and most infections occurred within 48 hours of operation. Chemotyping showed that most infections were caused by different strains, and cross infection by $H$ influenzae seemed to be rare. Cefuroxime given during anaesthesia did not prevent postoperative chest infection.

Non-capsulated Haemophilus influenzae strains are often carried in the healthy upper respiratory tract in man. Carriage rates vary widely and are usually higher in children and in closed communities than in the general adult population. ${ }^{1}$ These bacteria are most often responsible for infection in bronchi damaged by chronic bronchitis or related diseases. Their potential pathogenicity in patients about to undergo a surgical operation, however, is not well understood. Aspiration of bacteria from the throat into the lungs can occur during general anaesthesia. Hyperventilation, particularly after abdominal surgery, and impaired cough reflex also predispose such patients to postoperative chest infection. ${ }^{2}$

Chronic bronchial disease is closely associated with an increased risk of a postoperative chest infection. ${ }^{3}$ There is some evidence that age, a history of heavy smoking, and the site of operation also predispose surgical patients to such infection. ${ }^{45}$ The use of antimicrobials to prevent chest infections has received little attention. Prophylaxis for patients with chronic bronchtis has been recommended but has not always been successful. ${ }^{4}$ More study is needed to determine which group of patients will benefit most from prophylaxis, which antimicrobial agent should be chosen, and whether a single dose will suffice.

Accepted for publication 12 September 1985
A heavy growth of $H$ influenzae or Streptococcus pneumoniae is usually associated with clinical and ra- $\stackrel{0}{0}$ diological signs of chest infection. ${ }^{6}$ The prevalence of $\frac{\mathbb{Q}}{\mathscr{Q}}$ these infections varies with time, but the reasons for $\overrightarrow{\vec{A}}$ this are unclear. Undoubtedly, most infections are $\frac{0}{3}$ caused by micro-organisms, which the patient carries in the upper respiratory tract, and higher carriage rates may increase the level of infection. Secondary cases of disease, recognisable because the isolates belonged to the same chemotype, have been described, $\frac{5}{3}$ but only a limited number of infections have been studied. $^{7}$

This study was undertaken to investigate post-

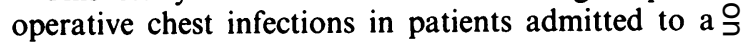
male general surgical ward.

\section{Premises, patients, and methods}

SURGICAL WARD

The ward, an open Nightingale type with natural ventilation, was located on the ground floor of a two storey building. It contained 30 beds available forco treating adult male patients. It was divided into two parts, one of which contained a high dependency area $\stackrel{\mathcal{P}}{+}$ into which patients were brought immediately after $\underset{T}{T}$ their operations. Later, patients were moved to an- $\frac{\vec{P}}{D}$

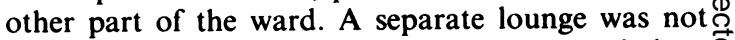
provided for ambulatory patients, and no restrictions $\stackrel{\mathbb{Q}}{\Omega}$ were placed on their movements on the ward. 


\section{PATIENTS}

In this study chronic bronchitis was defined as persistent cough with production of sputum on most days of three months of the year for at least the two preceding years. Table 1 shows the classification of the types of operations. Some patients who underwent abdominal surgery received two doses of cefuroxime and metronidazole, one dose of each antibiotic was given during anaesthesia and another dose of each six hours after operation.

A throat swab was collected by nursing staff from 200 patients admitted over six months in 1984 for elective surgery. Swabs were not obtained from patients admitted as emergencies, and because of the heavy workload on the ward at certain times throat swabs were occasionally not received from elective admissions. Information about age, smoking history, chronic bronchitis, and the reason for admission was requested. Later, the medical records of patients carrying $H$ influenzae on admission were reviewed.

It was standard practice on the surgical ward to collect at least two postoperative sputum samples from patients who were feverish within 48 hours of operation, or who showed clinical evidence of a postoperative chest infection.

The records of the following groups of patients were also studied: patients admitted to the ward during 1984 from whom a postoperative sputum sample was received; patients on the ward in whom $H$ influenzae was isolated from a postoperative sputum sample between January 1982 and March 1985.

\section{METHODS}

Sputum specimens were homogenised and processed as previously described. ${ }^{8}$ Strains were isolated on Columbia agar containing horse blood $5 \%(\mathrm{v} / \mathrm{v})$, nicotinamide adenine dinucleotide (NAD) $10 \mathrm{mg} / \mathrm{l}$, and haemin $10 \mathrm{mg} / \mathrm{l}$. For admission throat swabs, bacitracin $300 \mathrm{mg} / 1$ and amphotericin $2.5 \mathrm{mg} / 1$ were also added.

All strains showed satellite growth on Columbia agar around a paper disk containing haemin and NAD; they were non-haemolytic on horse blood agar and did not synthesise porphyrins from $\delta$ aminolaevulinic acid. ${ }^{9}$ All isolates were examined for capsules by a coagglutination technique (Phadebact Haemophilus test). For storage the strains were suspended in nutrient broth (Oxoid No 2) with glycerol $10 \%(\mathrm{v} / \mathrm{v})$ and were frozen at $-70^{\circ} \mathrm{C}$.

For typing studies three variants of the defined medium described previously ${ }^{7}$ were prepared: a medium omitting histidine; a medium omitting hypoxanthine; and a medium omitting glycine, isoleucine, leucine, lysine, methionine, serine, tryptophan, and tyrosine. The plates were stored at $4^{\circ} \mathrm{C}$ and used within four weeks of preparation. Typing was carried out as pre- viously described, ${ }^{7}$ except that cultures were incubated in air containing 5\% carbon dioxide for 36 hours before reading the results. Tests for indole production, urease activity, and for ornithine and lysine decarboxylase activity were as previously described. ${ }^{7}$

\section{Results}

\section{CARRIAGE OF H INFLUENZAE ON ADMISSION}

Admission throat swabs from eight patients grew enterobacteria, and because of the possible problems of overgrowth of $H$ influenzae by these micro-organisms, the patients were omitted from the study. Of the remaining 192 patients, 94 were admitted for abdominal operations, $\mathbf{4 0}$ for oral surgery, $\mathbf{4 8}$ for other types of surgery (Table 1), and 10 patients were not treated by operation. The mean age was 48 years (range 13-85 years). Forty one per cent of patients smoked more than ten cigarettes per day, and thirteen $(7 \%)$ were chronic bronchitics. A postoperative sputum sample was received from 36 patients. Of the chronic bronchitics, eight developed a postoperative chest infection and five, two of whom had received spinal anaesthesia, showed no clinical evidence of infection.

Of the 192 throat swabs, 28 grew $H$ influenzae (carriage rate $14.6 \%$ ). One isolate, from a patient aged 15 years, was of capsular type $b$, and the remaining strains were non-capsulated. A total of 13 chemotypes was recognised, and four strains failed to grow on the defined medium. The most common types were type 38 (four strains), type 42 (three strains), type 52 (four strains), and type 55 (three strains). Ten of the 28 patients developed postoperative chest infections; three of which were due to $H$ influenzae, one was due to Branhamella catarrhalis, and one was caused by Pseudomonas aeruginosa. No bacterial pathogen was isolated in the other five cases. Two of the three isolates of $H$ influenzae were from chronic bronchitics. In each of these cases the strains isolated before and after operation were of the same chemotype. The other $H$ influenzae isolated was from a patient with a history of heavy smoking but who was not a chronic bronchitic. In this case the strains isolated before and after surgery were not identical; type 55 from the admission swab and type 28 from the sputum specimen.

\section{POSTOPERATIVE CHEST INFECTIONS IN 1984}

One hundred and ninety eight sputum specimens were received from 113 patients. Of these, seven did not have an operation, and the records of three patients were not available for study. Of the 103 patients, 89 had undergone abdominal surgery, and 14 were treated by other types of surgery. No post-operative chest infections were observed in patients after oral surgery. The mean age was 59.5 years (range 17-95 years). Seventy three per cent of patients smoked more 
Table 1 Classification of operations in three study groups

\begin{tabular}{|c|c|c|c|}
\hline Operation & Admission swab* & Postoperative sputum $†$ & Chemotyping $\ddagger$ \\
\hline $\begin{array}{l}\text { Abdominal: } \\
\text { Oesophagectomy } \\
\text { Vagotomy } \\
\text { Cholecystectomy } \\
\text { Laparotomy } \\
\text { Splenectomy } \\
\text { Appendicectomy } \\
\text { Hernia repair } \\
\text { Colectomy } \\
\text { Anterior resection } \\
\text { Repair of aortic aneurysm }\end{array}$ & $\begin{array}{r}2 \\
22 \\
9 \\
9 \\
2 \\
9 \\
29 \\
4 \\
6 \\
2\end{array}$ & $\begin{array}{r}6 \\
22 \\
11 \\
15 \\
2 \\
7 \\
13 \\
5 \\
6 \\
2\end{array}$ & $\begin{array}{r}3 \\
27 \\
5 \\
7 \\
1 \\
1 \\
14 \\
6 \\
7 \\
1\end{array}$ \\
\hline $\begin{array}{l}\text { Oral: } \\
\text { Dental extraction } \\
\text { Abscess drained } \\
\text { Traumatic jaw injury }\end{array}$ & $\begin{array}{r}32 \\
4 \\
4\end{array}$ & $\begin{array}{l}0 \\
0 \\
0\end{array}$ & $\begin{array}{l}0 \\
0 \\
0\end{array}$ \\
\hline $\begin{array}{l}\text { Other: } \\
\text { Femoral artery graft } \\
\text { Lower limb amputation } \\
\text { Varicose veins } \\
\text { Rectal surgery } \\
\text { Testicular surgery } \\
\text { Plastic surgery and node biopsy }\end{array}$ & $\begin{array}{r}8 \\
4 \\
8 \\
13 \\
8 \\
7\end{array}$ & $\begin{array}{l}7 \\
3 \\
1 \\
2 \\
0 \\
1\end{array}$ & $\begin{array}{l}5 \\
1 \\
0 \\
1 \\
0 \\
0\end{array}$ \\
\hline
\end{tabular}

* Throat swabs collected over six months.

+Postoperative sputum specimens received from 103 patients in 1984.

†Specimens from 74 patients admitted between January 1982 and March 1985.

than ten cigarettes per day or had done so until recently, and $34 \%$ were chronic bronchitics.

Potentially pathogenic bacteria were isolated from 42 patients (Table 2). $H$ influenzae was the most common respiratory pathogen and accounted for $56 \%$ (27/48), of pathogens isolated. Infections with $H$ influenzae or $S$ pneumoniae usually occurred during the early postoperative period (mean 3.4 days and $4 \cdot 2$ days, respectively), and infections caused by $B$ catarrhalis occurred on average 6.2 days after operation. In contrast, enterobacteria and $P$ aeruginosa infections occurred late (mean 14.3 days after operation), and were rarely seen in patients who had not received antibiotics.

\section{CHEMOTYPING OF STRAINS OF H INFLUENZAE}

Between January 1982 and March 1985, $H$ influenzae was isolated from 74 patients ( 24 of whom have been described previously $\left.{ }^{7}\right)$. The mean age was $58 \cdot 1$ years (range 22-82 years). Most isolates were from patients who had undergone abdominal surgery (72/79 operations) (Table 1). Three patients were admitted to the ward on more than one occasion during the study period. Eighty six per cent of patients had a history of heavy smoking. Twenty three patients were chronic bronchitics, and a further 16 reported occasional productive coughs, particularly during the winter months. Thirty patients received antimicrobial prophylaxis before abdominal surgery (cefuroxime and metronidazole), and three patients were given cloxacilin before aortofemoral graft operations.

The Figure shows the strains of $H$ influenzae isolated from sputum specimens according to month and the number of beds occupied on the ward. There was

Table 2 Micro-organisms isolated from 42 of 103 patients with postoperative chest infections on male surgical ward

\begin{tabular}{|c|c|c|c|c|c|c|}
\hline \multirow[t]{2}{*}{ Micro-organism } & \multicolumn{4}{|c|}{ Type of surgery } & \multicolumn{2}{|l|}{ Total No } \\
\hline & $\begin{array}{l}\text { Abdominal } \\
S^{*}\end{array}$ & $N S \dagger$ & $\begin{array}{l}\text { Other } \\
S^{*}\end{array}$ & $N S \dagger$ & Isolates & $\begin{array}{l}\text { Patients with chronic } \\
\text { bronchitis }\end{array}$ \\
\hline $\begin{array}{l}\text { Haemophilus influenzae } \\
\text { Streptococcus pneumoniae } \\
\text { Branhamella catarrhalis } \\
\text { Klebsiella spp } \\
\text { Escherichia coli } \\
\text { Pseudomonas aeruginosa } \\
\text { Staphylococcus aureus } \\
\text { Streptococcus pyogenes }\end{array}$ & $\begin{array}{r}22 \\
6 \\
5 \\
3 \\
0 \\
1 \\
1 \\
1\end{array}$ & $\begin{array}{l}1 \\
2 \\
0 \\
0 \\
0 \\
1 \\
0 \\
0\end{array}$ & $\begin{array}{l}4 \\
0 \\
0 \\
0 \\
1 \\
0 \\
0 \\
0\end{array}$ & $\begin{array}{l}0 \\
0 \\
0 \\
0 \\
0 \\
0 \\
0 \\
0\end{array}$ & $\begin{array}{r}27 \\
8 \\
5 \\
3 \\
1 \\
2 \\
1 \\
1\end{array}$ & $\begin{array}{r}14 \\
3 \\
3 \\
1 \\
0 \\
1 \\
0 \\
1\end{array}$ \\
\hline Total & 39 & 4 & 5 & 0 & $48 \ddagger$ & 23 \\
\hline \multicolumn{7}{|c|}{$\begin{array}{l}\text { *S }=\text { smoker, }+N S=\text { non-smoker. } \\
\text { †Five patients had mixed infections. }\end{array}$} \\
\hline
\end{tabular}




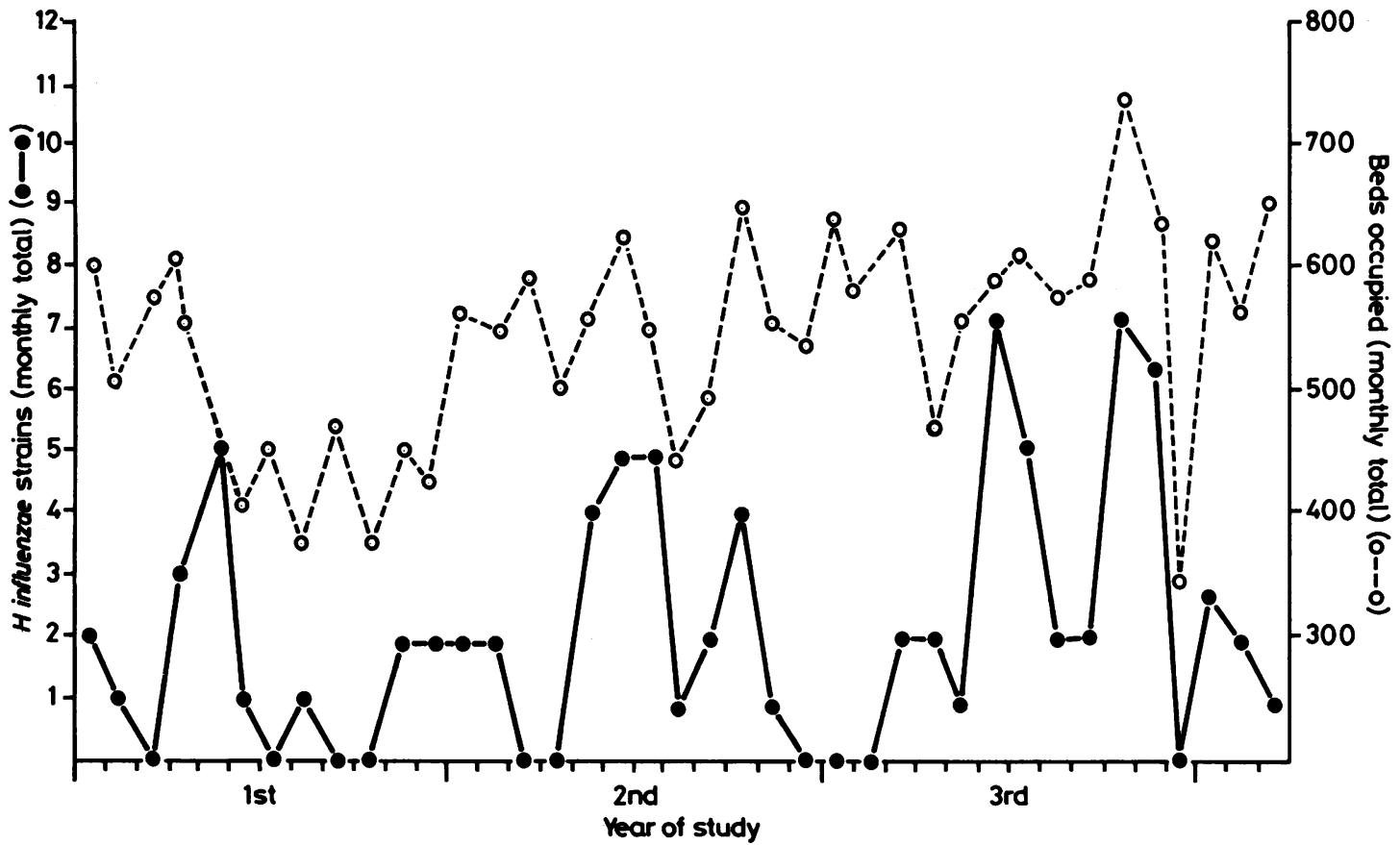

Incidence of postoperative $H$ influenzae chest infections between January 1982 and March 1985.

monthly total of $H$ influenzae strains; $\bigcirc--\bigcirc$ monthly total of beds occupied (an occupied bed at midnight counts as one unit).

some seasonal variation, and clusters of cases occurred during early summer in each of the three years studied and also during October in two of these years. Most infections occurred on or before the second postoperative day, but eleven strains were first isolated more than seven days after operation. Of the

Table 3 Chemotypes of 71 strains of Haemophilus influenzae from postoperative chest infections

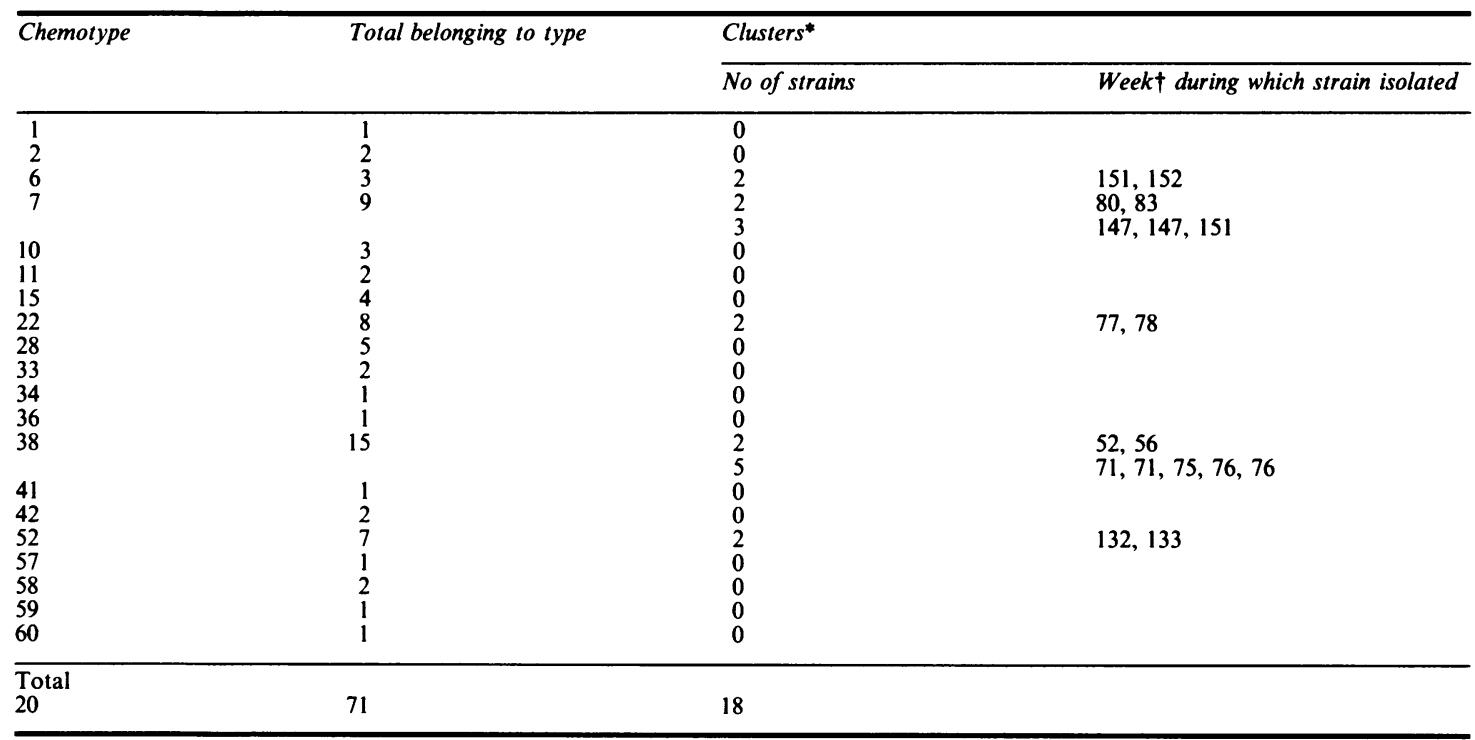

*A cluster $=$ two or more strains isolated over four weeks.

†Period of study 169 weeks (January 1982-March 1985). 
76 strains, 71 were assigned to 20 chemotypes (Table 3 ), one strain failed to grow on the medium, and four cultures were lost to the study. The largest groups were type $38(21 \%)$, type $7(13 \%)$, type $22(11 \%)$, and type $52(10 \%)$. Eighteen of the 71 strains were assigned to clusters containing two or more strains of the same chemotype isolated during one month (Table 3). $H$ influenzae of type 6 was isolated from two patients who were treated at the same time in the high dependency area of the ward. One of these patients was admitted as an emergency and was known to be infected with the micro-organism on admission. As this chemotype was rare among patients on the ward cross infection seems probable. Clusters were also observed with types 7, 22, 38, and 52. Although some of these patients were nursed at the same time in the high dependency area, strains of these types were frequently isolated during the study, and further subdivision is needed to determine whether cross infection had occurred.

\section{Discussion}

In family and institutional studies for $H$ influenzae carriage rates between $32 \%$ and $82 \%$ were found in adults. ${ }^{1}$ These rates may be partly associated with high levels of atmospheric pollution and those in early studies to the misidentification of some strains. A lower carriage rate can be expected in the general adult population. Although a selective isolation medium was used in this study for throat swabs, the rate of $14.6 \%$ may have been an underestimate because of the problem of isolating $H$ influenzae from other upper respiratory tract flora. The examination of more than one specimen would have been belpful.

The detection of $H$ influenzae in sputum is not always successful, but it is helped by homogenisation and dilution of the specimen before culture and by the examination of more than one sputum sample; these procedures were carried out in this study. Possibly, some patients with postoperative chest infections failed to produce a sputum specimen and were, therefore, excluded from this study, but the extent to which this occurred is unknown.

In general, preoperative carriage of $H$ influenzae did not predispose patients to chest infection after surgery. Routine screening on admission of patients who were previously healthy seemed to have no value. Patients with chronic bronchitis who were carrying $H$ influenzae on admission, however, did develop postoperative chest infections with the micro-organism, and this group of people seems to be at higher risk.

The results of this study agree with those of other workers in respect of age, a history of heavy smoking, and the type of operation, all of which were found to affect the incidence of postoperative chest compli- cations. ${ }^{45}$ It seems that cefuroxime had little effect on the incidence of postoperative chest infections, although this antibiotic is highly active in vitro against $H$ influenzae. In general, penicillins and cephalosporins are ineffectual in prophylaxis, and recent studies have shown that rifampicin is better at eliminating the carriage of $H$ influenzae of capsular type b. ${ }^{10}$ There is no evidence to suggest that passage of antimicrobial agents into the nasopharyngeal secretions is sufficient to suppress $H$ influenzae in patients with chronic bronchial disease. Inhaled antimicrobial agents have been used with some success in patients with cystic fibrosis ${ }^{11}$ and might also be considered in other chronic lung diseases. Although the value of antimicrobial agents in preventing chest infection remains uncertain, this study has confirmed the clinical importance of $\boldsymbol{H}$ influenzae in postoperative chest infections; and when antimicrobial prophylaxis is used an agent likely to be effective against this microorganism should be chosen.

From time to time clusters of $H$ influenzae infections occurred on the ward, but chemotyping usually showed that various strains were entailed. Such clusters may reflect the heavy workload on the ward at these times or be due to an increased nasopharyngeal carriage rate. Surprisingly, however, few infections occurred during the winter months when the incidence of chest infection in the community was high and the ward was busy: a seasonal variation in the carriage of $H$ influenzae was not observed in the admission swab study, but the period of investigation may have been too short for this to be identified.

As most $H$ influenzae infections occurred during the early postoperative period they were probably induced by anaesthesia or some other factor related to the operation. Five patients who developed postoperative chest infections due to $H$ influenzae, however, had negative admission swabs. Perhaps the method used to detect patients carrying $H$ influenzae on admission was inadequate, or the patients may have rapidly acquired the micro-organisms on the ward or in theatre. Most elective operations were performed on the patient's third day in hospital. When clusters of infections were studied cross infection probably occurred on one occasion, but in most cases evidence for it was inconclusive. These results suggest that cross infection plays a minor role in the large number of postoperative chest infections caused by $H$ influenzae.

I thank Drs E McKay-Ferguson and M Barnham for advice during the preparation of the manuscript, $\mathrm{Mr}$ WM Cooke and Mr D Clarke for access to the medical records of patients under their care, and Mrs MC Davies, medical records officer, Middlesbrough General Hospital. I am also grateful to Mrs ME McClus- 
key, nursing officer, control of infection, and to the nursing staff who collected the admission throat swabs.

Requests for reprints to: Dr GM Tebbutt, Public Health Laboratory, South Cleveland Hospital, Marton Road, Middlesbrough, Cleveland TS4 3TA, England.

\section{References}

${ }^{1}$ Turk DC, May JR. Haemophilus influenzae: its clinical importance. London: The English Universities Press, 1967:13-23.

${ }^{2}$ Anonymous. Postoperative chest infections. [Editorial]. $\mathrm{Br} \mathrm{Med} \mathrm{J}$ 1977;ii:1500-1.

${ }^{3}$ May JR. The chemotherapy of chronic bronchitis and allied disorders. London: The English Universities Press, 1968:87-9.

${ }^{4}$ Lazlo G, Archer GG, Darrell JH, Dawson JM, Fletcher CM. The diagnosis and prophylaxis of pulmonary complications of sur- gical operation. Br J Surg 1973;60:129-34.

${ }^{5}$ Collins CD, Dark CS, Knowelden J. Chest complications after upper abdominal surgery: their anticipation and prevention. $\mathrm{Br}$ Med J 1968;i:401-6.

${ }^{6}$ Wilkinson PJ, Ball AJ, Doran J, Gillespie WA, Orton VS. Routine laboratory assessment of postoperative chest infection: a prospective study. J Clin Pathol 1977;30:417-20.

${ }^{7}$ Tebbutt GM. A chemotyping scheme for clinical isolates of Haemophilus influenzae. J Med Microbiol 1984;17:335-45.

${ }^{8}$ Tebbutt GM, Coleman DJ. Evaluation of some methods for the laboratory examination of sputum. J Clin Pathol 1978;31:724-9.

${ }^{9} \mathrm{Kilian}$ M. A rapid method for the differentiation of Haemophilus strains. The porphyrin test. Acta Pathol Microbiol Scand 1974;82B:835-42.

${ }^{10}$ Granoff DM, Daum RS. Spread of Haemophilus influenzae type b: recent epidemiologic and therapeutic considerations. $J$ Pediatr 1980;97:854-60.

${ }^{11}$ Hodson ME, Penketh ARL, Batten JC. Aerosol carbenicillin and gentamicin treatment of Pseudomonas aeruginosa infection in patients with cystic fibrosis. Lancet 1981;ii:1137-9. 